\title{
Pattern and risk factors of acute poisoning in a tertiary hospital of Central Bangladesh
}

\author{
Mohammad Rafiqul Islam', Sarmistha Biswas², Syed Zakir Hossain³, Nafizul Islam4, Gourab Dewan5, \\ Mohammad Robed Amin ${ }^{*}$
}

1 Department of Medicine, Shaheed M Monsur Ali Medical College, Sirajganj, Bangladesh

${ }^{2}$ Department of Medicine, Dhaka Medical College, Dhaka, Bangladesh

${ }^{3}$ Department of Medicine, Shahid Syed Nazrul Islam Medical College, Kishoreganj, Bangladesh

${ }^{4}$ Department of Medicine, Shariatpur Sadar Hospital, Shariatpur, Bangladesh

${ }^{5}$ Department of Medicine, Rangamati Medical College, Rangamati, Bangladesh

\author{
Received: 5 April 2018 \\ Accepted: 4 July 2018 \\ Published online: 12 July 2018 \\ *Corresponding author: \\ Mohammad Robed Amin, \\ Postal Address: Medicine unit VII \\ Department of Medicine, Dhaka \\ Medical College Hospital. \\ Email: robedamin@yahoo.com \\ Competing interests: None. \\ Funding information: None. \\ Citation: Islam MR, Biswas S, \\ Hossain SZ, Islam N, Dewan G, Amin \\ MR. Pattern and risk factors of acute \\ poisoning in a tertiary hospital \\ of Central Bangladesh. Journal of \\ Emergency Practice and Trauma \\ 2019; 5(1): 23-28. doi: 10.15171/ \\ jept.2018.11
}

\begin{abstract}
Objective: Acute poisoning is a common cause of hospital admission in Bangladesh. But, risk factors and characteristics of victims of different modes of poisoning have not been evaluated for possible intervention strategies. So, in this study we aimed to describe the pattern of acute poisoning in central Bangladesh as well as identifying risk factors for various mode of poisoning. Methods: A prospective observational study was undertaken in Dhaka Medical College Hospital in 2015. Consenting adult acute poisoning victims were included as study subjects. A pretested structured case record form was used to systematically record the cases. The poisoning cases were defined by clinical toxidrome (sympathomimetic, antimuscarinic, opioids, cholinergic, sedative, etc) during acute presentation with suspected poisoning and groups accordingly. SPSS 20 was used for data analysis and statistical tests including mean \pm standard division (SD), percentage, $t$ test and chi-square were used accordingly.

Results: Total poisoning cases were 1155 . Suicidal $(62.25 \%, n=719)$, commuter poisoning $(24.16 \%, n=279)$ and accidental poisoning $(12.38 \%, n=143)$ were main types of poisoning. Risk factors of suicidal poisoning were young females of 11 to 30 years, married, housewives and students $(P<0.0001)$. Stressful relationship was the commonest reason of suicidal poisoning. Pesticides and sedatives were frequently chosen for easy availability. Commuter poisoning was common in males and urban areas $(P<0.0001)$. Accidental poisoning was more in males and rural areas $(P<0.0001)$ and snake envenomation was the main cause.

Conclusion: Poisoning burden is high in central Bangladesh. Identified risk factors will help develop poisoning prevention strategies.

Keywords: Bangladesh, Poisoning, Suicide, Prevention
\end{abstract}

\section{Introduction}

Acute poisoning is a common medical emergency in Bangladesh. It is the seventh commonest cause of inhospital mortality in Bangladesh (1). Everyday cases are admitted in different units in the same hospital and different variety of agents are implicated- pesticides, weedicides, rodenticides, chemical substances, variety of drugs, plant products, methanol, travel related poisoning of commuters, snakebite, scorpion and insect stings, fish poisoning etc. Patient load is sometime very high and there is uncertainty whether all cases are recorded. The first two days are very critical and require critical/high dependency care for stabilization of the condition. It may require cardiac monitoring, oxygen/nebulisation, fluid/ respiratory support, and renal electrolyte assessment. Multiple organ failure may occur which need intense monitoring and there is difficulty to have multiple facilities in the same hospital.

Huge burden of poisoning requires comprehensive intervention strategies and effective management to reduce case burden and mortality. In the absence of a poison information center in Bangladesh, hospital based toxicovigilance can provide toxico-epidemiological information to design focused interventions. In the past years, epidemiological studies described the clinical presentations and poisoning agents. Background of the victims and their relation with different mode of poisoning is yet to be evaluated. A better understanding of the victims and risk factors of poisoning may help identify the vulnerable groups and offer scope for preventive interventions.

Mortality due to pesticide poisoning has been found 
to be $14-15 \%$ in developing countries in comparison to $<1 \%$ in the developed world (2). The Director General Health Service (DGHS) reported cases from 1988 to 1996 on hospital records at the district level and below. It has been observed that the incidence of poisoning has been on increase gradually since 1988 to 1996 except in 1990 and 1993 (3). Recent epidemiological data on acute poisoning cases from central Bangladesh (Dhaka division) consisting of 47.42 million populations is unavailable (4). With this background in mind, we aim to describe the pattern of poisoning and characteristics of victims according to modes of poisoning. This may identity the factors related to different mode of poisoning and help us suggest strategies to reduce poisoning burden.

\section{Methods}

This descriptive cross-sectional study was undertaken from May to August 2015 on 1155 poisoning cases who referred to adult medicine ward of Dhaka Medical College Hospital (DMCH). It is a tertiary level hospital in the capital of Dhaka and 17 districts of Dhaka division. Consenting adult acute poisoning victims were included as study subjects. A pretested structured case record form was used to systematically record the cases. Two working medical officers were trained for appropriate entry of data in the case record form. Patients with suspected poisoning who were brought dead or declined to participate were excluded. The poisoning cases were defined by clinical toxidrome (sympathomimetic, antimuscarinic, opioids, cholinergic, sedative, etc) during acute presentation with suspected poisoning and groups accordingly. Any brought sample for identification was encouraged by the patient or attendant. Due to lack of toxicological lab in our country, there was no attempt to establish different poisoning categories through biochemical analysis. The management of poisoning cases was done according to consultant's discretion in corresponding unit.

Observed variables were age, gender, marital status, residence, educational qualification, occupation, mode of poisoning, reason of poisoning, poisoning agents and outcome. Continuous data were presented using mean \pm $\mathrm{SD}$; while categorical data were presented as percentage. Difference in categorical variables between sub-groups was evaluated using chi-square test or student's $t$ test for continuous data as applicable and level of significance was set at $P<0.05$ with $95 \%$ CI. SPSS version 20 manufactured by Chicago, Illinois was used for analysis.

\section{Results}

The total number of poisoning cases was 1155 . Estimated poisoning cases were $3.59 / 100000$ per population $\left(15^{+}\right)$. Detailed socio-demographic characteristics of the poisoning victims, according to the mode of poisoning, are shown in table 1 . Male $(\mathrm{n}=594)$ to female $(\mathrm{n}=561)$ ratio was almost equal (1: 0.9$)$. The mean age was 27.17 \pm 11.63 years. The majority were in the 21 to 30 -year age group $(38.71 \% ; \mathrm{n}=444)$, followed by the 11 to 20 -year age group (33.22\%; $\mathrm{n}=381$ ). Suicidal poisoning was mostly seen in the 11 to 30 -year age group. The proportion of females was significantly higher than males $(P<0.0001)$. Suicidal poisoning was less in women aged $>30$ years $(9.93 \%, \mathrm{n}=47)$. The mean age of suicidal poisoning varied significantly by gender (males $26.95 \pm 11.18$ years, females $22.68 \pm 7.22$ years; $P=0.0001)$. The mean age of students attempting suicide was $18.12 \pm 3.14$; the lowest in any subpopulation. Commuter poisoning was frequent in 21 to 40-year age group. Accidental poisoning was the most common in 11 to 30-year age group. Subjects were more of urbans $(70.82 \% ; n=818)$ rather than the people with rural background $(29.18 \%, \mathrm{n}=337$ ) (Table 1 ).

The main mode of poisoning was suicidal $(62.25 \%,) \mathrm{n}=$ 719; CI 59.42 to 65.00 ), followed by stupefying poisoning $24.16 \%$ ( $\mathrm{n}=279$; CI 21.78 to 26.71 ), and unintentional (accidental) $12.38 \%(n=143$; CI 10.60 to 14.41$)$ and homicidal $0.69 \%(\mathrm{n}=8$, CI 0.35 to 1.36$)$. In the remaining six cases, the mode of poisoning was undetermined (5.22\%).

Reasons of poisoning (as shown in Table 2) included stressful relationship $61.76 \%(\mathrm{n}=679$; CI 58.73 to 64.72 ), facilitation of criminal act by stupefying $27.63 \%(n=279$; CI 25.03 to 30.56), poor academic achievement 1.98\%, (n $=20$, CI 12.90 to 30.50 ), economic loss $1.88 \%$ ( $\mathrm{n}=19$, CI 12.10 to 29.30$)$ and miscellaneous $6.65 \%(n=67$; CI 5.27 to 8.36$)$.

Stressful relationship was prevalent in females than males $(P<0.0001)$. In addition, it was higher in 10 to 30 -year age group $(67.63 \% ; n=558)$ than those aged $>31$ years $(38.10 \% ; n=125)$. Interestingly, stressful relationship was prevalent in unmarried $(58.88 \% ; \mathrm{n}=252)$ than married (51.70\%; $\mathrm{n}=365)$. Causes of stress or family disharmony included spousal violence, problem in affair, dowry, family feud, social humiliation or stigmatization.

Stressful relationship was responsible for 98.18\% ( $\mathrm{n}=$ 271) of suicidal poisoning attempts among housewives and $81.27 \%(\mathrm{n}=217)$ of students. Although poisoning is common during sudden decision of an acute stressful event, this study revealed an history of preexisting psychological disorder in $1.80 \%(n=13)$ of suicidal cases (Table 2).

Characteristics of vulnerable groups described according to mode of poisoning (Table 3). It shows mean age, gender, residence and profession of victims are different for suicidal and accidental poisoning.

The most common poisoning agents were commuter poisoning with unidentified substances, sedatives and pesticides. In rural areas, snake envenomation was the commonest $(17.61 \% ; \mathrm{n}=59)$ followed by organophosphates (OP) $(16.71 \% ; \mathrm{n}=56)$. In urban areas, pharmaceutical agents of the benzodiazepine class (BDZ) $(16.23 \% ; n=132)$ was the main agent followed by OPs $(7.75 \% ; n=63)$. For suicidal poisoning; sedatives $(24.12 \% ; n=173)$ and pesticides $(20.22 \% ; n=145)$ were 
Table 1. Sociodemographic characteristics of the patients according to mode of poisoning

\begin{tabular}{|c|c|c|c|c|c|c|c|c|}
\hline \multirow{2}{*}{ Characteristics } & \multicolumn{2}{|c|}{ Suicidal poisoning } & \multicolumn{2}{|c|}{ Stupefying poisoning } & \multicolumn{2}{|c|}{ Unintentional Poisoning* } & \multicolumn{2}{|c|}{ Homicidal poisoning } \\
\hline & No. & $\%$ & No. & $\%$ & No. & $\%$ & No. & $\%$ \\
\hline \multicolumn{9}{|l|}{ Gender } \\
\hline Male & 238 & 40.48 & 267 & 45.40 & 81 & 13.77 & 2 & 0.34 \\
\hline Female & 481 & 85.74 & 12 & 2.39 & 62 & 11.05 & 6 & 1.07 \\
\hline \multicolumn{9}{|l|}{ Age (y) } \\
\hline 11 to 20 & 308 & 42.99 & 23 & 8.27 & 45 & 31.46 & 3 & 37.5 \\
\hline 21 to 30 & 303 & 42.43 & 88 & 31.65 & 46 & 32.16 & 5 & 62.5 \\
\hline 31 to 40 & 70 & 9.87 & 84 & 30.21 & 22 & 15.38 & - & - \\
\hline 41 to 50 & 18 & 2.54 & 56 & 20.14 & 21 & 14.68 & - & - \\
\hline$\geq 51$ & 15 & 2.24 & 27 & 9.71 & 9 & 6.29 & - & - \\
\hline \multicolumn{9}{|l|}{ Residence } \\
\hline Rural & 206 & 61.68 & 56 & 16.77 & 68 & 20.35 & 4 & 1.71 \\
\hline Urban & 513 & 62.94 & 223 & 27.36 & 75 & 9.20 & 4 & 0.49 \\
\hline \multicolumn{9}{|l|}{ Education } \\
\hline Illiterate & 31 & 50.00 & 20 & 32.26 & 11 & - & - & 17.74 \\
\hline Undergraduate* & 509 & 62.07 & 199 & 24.27 & 112 & 13.66 & 8 & 0.97 \\
\hline Graduate & 69 & 49.64 & 53 & 38.13 & 17 & 12.23 & - & - \\
\hline Post graduate & 2 & 33.33 & 3 & 50.00 & 1 & 16.67 & - & - \\
\hline \multicolumn{9}{|l|}{ Marital status } \\
\hline Married 705 & 395 & 56.03 & 222 & 31.49 & 83 & 11.77 & 5 & 0.71 \\
\hline Unmarried 433 & 315 & 72.97 & 56 & 12.93 & 58 & 13.39 & 3 & 0.69 \\
\hline Others & 3 & 60.00 & - & - & 2 & 40.00 & - & - \\
\hline \multicolumn{9}{|l|}{ Occupation } \\
\hline House wife 323 & 276 & 85.44 & 5 & 1.55 & 38 & 11.76 & 4 & 1.24 \\
\hline Student & 272 & 83.64 & 13 & 4.01 & 39 & 12.03 & 1 & 0.31 \\
\hline Service & 72 & 37.89 & 100 & 52.63 & 17 & 8.95 & 1 & 0.53 \\
\hline Business & 45 & 24.32 & 120 & 64.85 & 20 & 10.81 & - & - \\
\hline Farmer & 11 & 39.28 & 4 & 14.28 & 13 & 46.42 & - & - \\
\hline Others & 43 & 41.93 & 37 & 39.16 & 16 & 17.20 & 2 & 2.15 \\
\hline
\end{tabular}

*Undergraduate $=$ grade $\mathrm{VI}$ to $\mathrm{XII}$.

Table 2. Provocative factors of poisoning

\begin{tabular}{|c|c|c|c|c|c|c|c|c|c|c|}
\hline & \multicolumn{2}{|c|}{ Stressful relationship } & \multicolumn{2}{|c|}{ Poor academic performance } & \multicolumn{2}{|c|}{ Economic loss } & \multicolumn{2}{|c|}{ Stupefying } & \multicolumn{2}{|c|}{ Others } \\
\hline & No. & $\%$ & No. & $\%$ & No. & $\%$ & No. & $\%$ & No. & $\%$ \\
\hline \multicolumn{11}{|l|}{ Gender } \\
\hline Male & 206 & 40.63 & 9 & 1.77 & 19 & 3.75 & 267 & 52.66 & 6 & 1.18 \\
\hline Female & 473 & 94.79 & 11 & 2.20 & - & - & 12 & 2.40 & 3 & 0.60 \\
\hline \multicolumn{11}{|l|}{ Occupation } \\
\hline Housewife & 280 & 98.24 & - & - & - & - & 5 & 1.76 & - & - \\
\hline Student & 254 & 88.19 & 20 & 6.94 & 1 & 0.35 & 13 & 4.51 & - & - \\
\hline Service & 70 & 40.00 & - & - & 5 & 2.86 & 100 & 57.14 & - & - \\
\hline Business & 37 & 22.42 & - & - & 8 & 4.85 & 120 & 72.72 & - & - \\
\hline Farmer & 9 & 60.00 & - & - & 2 & 13.33 & 4 & 2.67 & - & - \\
\hline Others & 33 & 42.30 & - & - & 3 & 3.85 & 36 & 46.15 & 6 & 7.69 \\
\hline \multicolumn{11}{|c|}{ Mode of poisoning } \\
\hline Suicide & 617 & 86.41 & 20 & 2.80 & 19 & 2.66 & - & - & 58 & 8.12 \\
\hline Commuter & - & - & - & - & - & - & 279 & 100.00 & - & - \\
\hline Homicidal & 5 & 62.50 & - & - & - & - & - & - & 3 & 37.50 \\
\hline
\end{tabular}

mainly used. In urban areas, sedatives and in rural areas, pesticides were predominant. Females preferred sedatives $(25.31 \%, \mathrm{n}=121)$ over pesticides $(17.78 \%, \mathrm{n}=$ $85)$, whereas males preferred pesticides $(25.53 \%, \mathrm{n}=60)$ over sedatives $(23.83 \%, \mathrm{n}=56)$ for suicidal attempts. Among household substances, Savlon ${ }^{\circledR}$ a combination of cetrimide + chlorhexidine $(n=51)$ and Harpic ${ }^{\circledR}$ a solution of hydrochloric acid $(\mathrm{n}=47)$ were frequent.
Most pesticide poisoning took place among housewives $(44.17 \%, \mathrm{n}=72)$ and students $(24.53 \%, \mathrm{n}=40) . \mathrm{BDZ}$ poisoning was the highest among students $(21.03 \%, \mathrm{n}=$ $69)$ and housewives $(17.33 \%, \mathrm{n}=56)$. Among businessmen $(64.86 \%, \mathrm{n}=120)$ and service holders $(52.08 \%, \mathrm{n}=100)$, commuter poisoning was prevalent. Snake envenomation was the commonest unintentional poisoning (69.93\%) in both rural and urban areas. It was an occupational hazard 
Table 3. Characteristics of vulnerable groups according to mode of poisoning

\begin{tabular}{|c|c|c|c|c|c|c|}
\hline \multirow{2}{*}{ Variable } & \multicolumn{2}{|c|}{ Suicidal poisoning } & \multicolumn{2}{|c|}{ Commuter poisoning } & \multicolumn{2}{|c|}{ Accidental poisoning } \\
\hline & Vulnerable group & $P$ & Vulnerable group & $P$ & Vulnerable group & $P$ \\
\hline \multicolumn{7}{|l|}{ Age } \\
\hline Mean age & $24.12 \pm 8.96$ & & $36.32 \pm 11.80$ & & $30.06 \pm 13.80$ & \\
\hline Age groups & 11 to 30 years & - & 21 to 40 years & - & 11 to 30 years & - \\
\hline Gender & Female $>$ male & $<0.0001$ & Male $>$ female & $<0.0001$ & Male $>$ female & 0.16 \\
\hline Residence & Rural and urban & 0.60 & Urban > rural & 0.0002 & Rural > urban & $<0.0001$ \\
\hline Occupation & $\begin{array}{c}\text { House wife } \\
\text { Student }\end{array}$ & $<0.0001$ & $\begin{array}{l}\text { Service holder } \\
\text { Businessman }\end{array}$ & $<0.0001$ & Farmer & $<0.0001$ \\
\hline Marital status & Married & $<0.0001$ & Married & $<0.0001$ & $\begin{array}{c}\text { Married and } \\
\text { unmarried }\end{array}$ & 0.42 \\
\hline Education & Undergraduate & $<0.0001$ & Undergraduate & 0.0013 & Illiterate & 0.57 \\
\hline
\end{tabular}

for farmers $(46.42 \%, \mathrm{n}=13)$ (Table 3 ).

Most of the victims survived $(64.40 \%, \mathrm{n}=740)$. A large number of victims left the hospital without the approval of hospital authorities $(31.24 \%, \mathrm{n}=359)$. Thus, their outcome was unknown. A small number of patients died $(1.74 \% ; \mathrm{n}=20)$. Suicidal poisoning resulted in 19 deaths $(95.00 \%)$ and the rest were from snake envenomation. The mortality rate among males was $1.86 \%(n=11)$ and among females was $1.61 \%(n=9)$. Among fatal cases, 12 were due to OP, sedative and snake bite (one for each) and the rest were from miscellaneous poisoning agents. Fatality among OP cases was $10.08 \%$ (Table 4).

\section{Discussion}

The burden of poisoning cases was high even in this short sphere of time frame. The highest number of poisoning

Table 4. Poisoning agents

\begin{tabular}{lcc}
\hline Poisoning agents & Number & Percent \\
\hline Pharmaceutical agent & 270 & 23.45 \\
Sedative & 159 & 13.83 \\
a) Benzodiazepine & 36 & 3.13 \\
b) Other sedatives & 75 & 6.49 \\
Miscellaneous drugs & 216 & 18.70 \\
Pesticide & & \\
Insecticide & 119 & 10.35 \\
a) Organophosphates & 25 & 2.17 \\
b) Carbamates & 53 & 4.59 \\
$\quad$ Rodenticide & 19 & 1.65 \\
Miscellaneous pesticides & 137 & 11.86 \\
\hline Household substances & 100 & 8.70 \\
Snake envenomation & 8 & 0.69 \\
\hline Kerosene & 7 & 0.60 \\
\hline Recreational drugs & & \\
(amphetamine, cannabis, marihuana) & 4 & 0.34 \\
\hline Corrosive agents & 3 & 0.26 \\
\hline Copper sulphate & 4 & 0.34 \\
\hline Methanol & 126 & 10.90 \\
\hline Miscellaneous & & 24.15 \\
\hline Unidentified (commuter) & & \\
\hline
\end{tabular}

a Herbal drugs, insect bite etc. was due to commuter poisoning $(24.19 \%)$. In an earlier study in $\mathrm{DMCH}$, commuter poisoning was the most common poisoning in three consecutive years $-46.6 \%$, $47.6 \%$ and $55.7 \%$ (2004-2006) (5). Conversely, our recorded frequency is much lower than prior studies. It may be either due to awareness created in different print media, television and different social media or maybe the study was done during a non-festival time. Like India, Pakistan, Turkey and Kenya, commuter poisoning is a common public health problem in Bangladesh (6-10). Indeed, this crime increases during the months of festival as during this period people used to carry money or goods and other valuable belongings while travelling from office or market places toward their home. In these series, regional difference in poisoning pattern exists. In Sylhet division (north-east region), the common poisonings were commuter, OP and sedative (11). In Khulna division (south-west region), it was OP, commuter poisoning and copper sulphate (12). In Rangpur division (northwest region), it was $\mathrm{OP}$, sedatives and corrosive $(12,13)$. Stupefying cases were about 6 times higher than selfharm among the population aged 31-50 years (14). This group travels more frequently. During travel, through transport, especially on bus or train, these people chat with unknown travel partners who convince them and invite them for snacks or drinks with them. Later, the poor victim becomes drowsy quickly and the criminals start their ill motive e.g. robbing, sexual abuse of girls, trafficking of children, etc (12). We observed commuter, sedatives and $\mathrm{OP}$ as common poisoning in the tertiary care center. In studies from Middle East (Iran and Palestine), animal envenomation was the commonest causative agent followed by pharmaceutical agents $(12,13)$.

A vast majority of studies are in line with our observation that adolescent and young adults (11 to 30 years) are the main victims of poisoning (11-13). But, middle aged were the main victims of commuter poisoning.

Gender ratio is similar to other studies from northern (1.4:1) and southern (1.14:1) Bangladesh with slight male predominance (12-14). However, in case of suicidal 
poisoning, the ratio was $1: 2$. In the 11 to 30 -year age group, females were more at the risk of attempted/ completed suicide than males. After the age of 30, males were more likely to attempt suicide by poisoning. Bari et al and Chowdhury et al also observed higher suicidal tendency among females with poison $(11,12)$. However, in Warangal district, Andhra Pradesh, India and Rangpur intentional poisoning was more common in males in all age groups $(11,15)$.

We obtained detailed characteristics of vulnerable groups of suicidal and commuter poisoning. Age and gender predilection for suicidal poisoning is like the pattern in developing countries. Literature about commuter poisoning is scarce. The mean age of our victims was high compared to previous studies due to the presence of elderly subjects. In a prior national study, the mean age of victims was $28.8 \pm 2.5$ years (3). In one study in India, it revealed that even Indian army personnel become the victims of commuter related poisoning and mean age was found 30.29 years (7) In Pakistan, most victims were males aged 26 to 35 years (16).

Suicide is a major public health concern in Bangladesh. Self-poisoning is the commonest method employed (17). Evidence shows that women aged 15 to 44 have the highest suicide rate in Bangladesh (17). Adolescent females (10 to 19 years) were the most vulnerable group (18). The adolescent groups were found to have attempted suicide in majority cases which is also consistent in previous studies. Reasons of familial disharmony/stressful relationship include the relationship breakup, repeated physical and sexual violence by spouse, emotional abuse defined as insult, humiliation, intimidation and threats (17). Suicidal ideation or attempts are significantly common in women exposed to such stressors in life $(17,19)$. Impulsive decision to end life following a bout of quarrel or tension is another stimulus. Most people who take poison do not wish to die; poisoning often happens from impulsive decision.

Careful intervention strategies may be practical in lowering self-poisoning and subsequent suicidal deaths. Strategies need to be directed towards the provocative factors and poisoning compounds (20). It is the suicidal ideation that leads to self-poisoning. Changing social attitude towards spousal violence, counseling for spousal violence, identification of victims and assistance before a fatal consequence occurs are some adoptable psychosocial strategies (17-20). Family counseling for conflict resolution and psychiatric counseling may help to lower the stress or impulse which leads to the decision of suicide. Availability of drugs without a physician's recommendation or failure to keep dangerous drugs in secured places is a common reason for the high prevalence of pharmaceutical agents as poison. Easy availability of pesticides makes them the commonest agents for poisoning in rural settings. Regulation of access (purchasing and keeping them in a secured place) to poisons and pharmaceutical agents are direct measures to reduce unwanted poisoning. Based on findings from China, India and Sri Lanka; a recent report by the World Health Organization (WHO) observed limitation of access to pesticides at community level to reduce the incidence of poisoning. This seems to be promising (21-23). Social awareness and strong vigilance by legal authorities may reduce commuter poisoning. In Bangladesh, mortality from poisoning cases was reported as $5.1 \%$ (17). Mortality in the current series was $1.7 \%$ which is lower than Khulna (7.36\%), Rangpur $(5.3 \%)$ and Sylhet $(5.1 \%)(11-14,17)$. Case fatality rate was the highest with OPs which was similar to Khulna $(13.88 \%, \mathrm{n}=73)$; but in Sylhet, the highest fatality was related to snake envenomation $(23.3 \%)(11,12)$. Mortality with OP (10.08\%) was higher than Sylhet (9.2\%) and Rangpur (5.4\%) but lower than Khulna (13.88\%) (11-13). Case fatality is less in our study. Dhaka Medical College is one of the best tertiary health care centers in Bangladesh. Continuous training of medical officers and academic members can make them skillful concerning acute poisoning and its management. Directorate General of Health office also took initiative to train medical officers at Upazila level about early management of acute poisoning. Possibly such actions play a pivotal role in reducing the mortality rate.

\section{Conclusion}

Poisoning cases are important hospital burdens in central Bangladesh. Addressing the identified provoking factors and focused interventions may be helpful to reduce the incidence of poisoning and suicide.

\section{Ethical issues}

Ethical and Scientific Committee of DMCH approved the study protocol.

\section{Authors' contributions}

MRA and MRI wrote the first draft. SB, SZH and NI edited and completed the draft. GD performed the statistical analysis and wrote the section related to analyses.

\section{References}

1. Directorate General of Health Services (DGHS). Bangladesh: Health Bulletin 2012. Dhaka: DGHS; 2012.

2. Srinivas Rao C, Venkateswarlu V, Surender T, Eddleston $\mathrm{M}$, Buckley NA. Pesticide poisoning in south India: opportunities for prevention and improved medical management. Trop Med Int Health 2005; 10(6): 581-8. doi: 10.1111/j.1365-3156.2005.01412.x.

3. Alam MS, Haq SM, Faiz MA, Hossain A. Assessment of Psychiatric condition in deliberate self-harm by OPC poisoning. Bangladesh J Psychiatry 1999; 13(1): 21-30.

4. Bangladesh Bureau of Statistics (BBS), Statistics and Informatics Division (SID), Ministry of Planning. Bangladesh Population and Housing Census 2011. Vol 4 (socio-economic and demographic report). Bangladesh, Dhaka: BBS; 2012.

5. Majumder MM, Basher A, Faiz MA, Kuch U, Pogoda 
W, Kauert GF, et al. Criminal poisoning of commuters in Bangladesh: prospective and retrospective study. Forensic Sci Int 2008; 180(1): 10-6. doi: 10.1016/j. forsciint.2008.06.016.

6. Ravi Ramamurthy H, Jaswal DS, Chaturvedi VP. “Travel travails" - Travel-related poisoning. Med J Armed Forces India 2013; 69(4): 409. doi: 10.1016/j.mjafi.2013.07.005.

7. Prakash J, Singh PK, Kotwal A, Ramakrishnan TS. Unknown Poisoning Amongst Serving Personnel. Med J Armed Forces India 2009; 65(1): 41-3. doi: 10.1016/s03771237(09)80053-1.

8. Nyamu DG, Maitai CK, Mecca LW, Mwangangi EM. Trends of Acute Poisoning Cases Occurring at the Kenyatta National Hospital, Nairobi, Kenya. East and Central African Journal of Pharmaceutical Sciences 2012; 15(2): 29-34

9. Senol E, Kaya A, Kocak A, Aktas EO, Erbas K, Islam M. Watch out for nuts in your travels: an unusual case of drugfacilitated robbery. J Travel Med 2009; 16(6): 431-2. doi: 10.1111/j.1708-8305.2009.00359.x.

10. Khan TM, Mehr MT, Ullah H, Abrar A. Drug-facilitated street and travel related crime: a new public health issue. Gomal J Med Sci 2014; 12(4): 205-9.

11. Bari MS, Chakraborty SR, Alam MMJ, Qayyum JA, Hassan N, Chowdhury FR. Four-Year Study on Acute Poisoning Cases Admitted to a Tertiary Hospital in Bangladesh: Emerging Trend of Poisoning in Commuters. Asia Pac J Med Toxicol 2014; 3(4): 152-6. doi: 10.22038/apjmt.2014.3485.

12. Chowdhury FR, Rahman AU, Mohammed FR, Chowdhury A, Ahasan HA, Bakar MA. Acute poisoning in southern part of Bangladesh--the case load is decreasing. Bangladesh Med Res Counc Bull 2011; 37(2): 61-5.

13. Sarkar D, Shaheduzzaman M, Hossain MI, Ahmed M, Mohammad N, Basher A. Spectrum of Acute Pharmaceutical and Chemical Poisoning in Northern Bangladesh. Asia Pac J Med Toxicol 2013; 2(1): 2-5. doi: 10.22038/apjmt.2013.508.
14. Amin MR, Basher A, Sattar A, Awal A, Sapan MR, Ghoseand A, et al. Baseline Survey on Cases of Poisoning and its Outcome in Bangladesh. Open Access Journal of Toxicology 2017; 2(2): 1-6. doi: 10.19080/OAJT.2017.02.555583.

15. Jalali A, Savari M, Dehdardargahi S, Azarpanah A. The pattern of poisoning in southwestern region of iran: envenoming as the major cause. Jundishapur J Nat Pharm Prod 2012; 7(3): 100-5.

16. Sawalha AF, Sweileh WM, Tufaha MT, Al-Jabi DY. Analysis of the pattern of acute poisoning in patients admitted to a governmental hospital in Palestine. Basic Clin Pharmacol Toxicol 2010; 107(5): 914-8. doi: 10.1111/j.17427843.2010.00601.x.

17. Dewan G. Analysis of Recent Situation of Pesticide Poisoning in Bangladesh: Is There a Proper Estimate? Asia Pac J Med Toxicol 2014; 3(2): 76-83.

18. Kumar SV, Venkateswarlu B, Sasikala M, Kumar GV. A study on poisoning cases in a tertiary care hospital. J Nat Sci Biol Med 2010; 1(1): 35-9. doi: 10.4103/0976-9668.71671.

19. Johnston HB, Naved RT. Spousal violence in Bangladesh: a call for a public-health response. J Health Popul Nutr 2008; 26(3): 366-77.

20. Mashreky SR, Rahman F, Rahman A. Suicide kills more than 10,000 people every year in Bangladesh. Arch Suicide Res 2013; 17(4): 387-96. doi: 10.1080/13811118.2013.801809.

21. Naved RT, Akhtar N. Spousal violence against women and suicidal ideation in Bangladesh. Womens Health Issues 2008; 18(6): 442-52. doi: 10.1016/j.whi.2008.07.003.

22. Mishara BL. Prevention of Deaths from Intentional Pesticide Poisoning. Crisis 2007; 28 Suppl 1: 10-20. doi: 10.1027/0227-5910.28.s1.10.

23. World Health Organization (WHO). Safer access to pesticides for suicide prevention: Experiences from community interventions; 2016 [cited 2018 Agu 4]. Available from: http://apps.who.int/iris/ bitstream/10665/246233/1/ WHO-MSD-MER-16.3-eng. pdf. 